\title{
A Corpus-Based Study of Heteroglossic Features in 2018 BRICS Talk from the Perspective of Engagement System
}

\author{
Guihang Guo ${ }^{1}$, Danni $\mathrm{Xu}^{1}$ \\ ${ }^{1}$ School of English for International Business, Guangdong University of Foreign Studies, China \\ Correspondence: Guihang Guo, School of English for International Business, Guangdong University of Foreign \\ Studies, No.2 Baiyundadaobei, Guangzhou 510420, P.R. China. Tel: 0086-13922423319.
}

Received: Mar. 20, 2020

doi:10.5430/elr.v9n2p1

\author{
Accepted: Apr. 27, $2020 \quad$ Online Published: Apr. 30, 2020 \\ URL: https://doi.org/10.5430/elr.v9n2p1
}

\begin{abstract}
Under the guidance of engagement system, which belongs to appraisal theory, this study analyzes data from 2018 BRICS talk through both quantitative and qualitative approaches. Quantitative approach is used to find out the list, characteristics and frequency of engagement resources of the speakers' utterance. Qualitative approach is employed to explore what interpersonal meaning it implies and how speakers position their own voices among the multi-voices. The results show that the theme of 2018 BRICS talk is about cooperation, development, unilateralism, protectionism, and opportunity for BRICS. With regard to engagement resources, expansion resources are used much more frequently than contraction resources. Furthermore, most of the speakers prefer entertain resources, especially, median and low value of modality resources. Within contraction sub-system, speakers are more willing to use disclaim rather than proclaim to contract dialogic space because proclaim may present more obvious subjective intervention. The engagement distribution features do present interpersonal meaning of BRICS members. On one hand, speakers tend to open up the dialogic space and welcome different opinions from other BRICS members, which indicates that a harmonious discussion atmosphere is established in 2018 BRICS talk. Moreover, median and low values of modality make it easier for audience to accept their points of view and helpful to establish solidarity with other BRICS members because high value modality is sort of assertive. On the other hand, the 2018 BRICS Talk is about sensitive political issues including protectionism, unilateralism and the 4th industry revolution. Therefore, opinions on those topics unavoidably differ from each other. In such cases, speakers prefer to use disclaim resources to reject others' opinion so as to make clear their own points of view.
\end{abstract}

Keywords: theme, engagement resources, BRICS, interpersonal meaning

\section{Introduction}

From 2018 to now, the trade war launched by the United States against the world has become fiercer, which has led to catastrophic consequences. No country will win in the trade war. Instead, in order to promote common development and achieve win-win and mutual benefit, it is advisable for all countries to work together so as to achieve globalization, cooperation and free trade. Under the prevalence of unilateralism and trade protectionism, it is particularly important for emerging markets to unite with each other to fight against protectionism and promote common development. BRICS bloc, emerging markets with promising growth prospects which consists of China, Russia, India, Brazil and South Africa, play an important role in global economic development.

2018 BRICS talk, held when trade war was provoked, is concerned with the hot issues mentioned above. Thus, 2018 BRICS talk was chosen as corpus of this study. Appraisal theory, put forward by Martin and White, is to enrich and complement interpersonal function, one of the three metafunctions put forward by Halliday (2004). Appraisal theory consists of three sub-systems, namely, attitude, engagement and graduation. Engagement system is further divided into monogloss and heterogloss. Heterogloss is based on Bakhtin's dialogism and multilingualism. Bakhtin (1998) holds that language is a dynamic process realized by the interaction between speakers and social speech. Within heterogloss subsystem, it includes dialogic expansion and dialogic contraction. The distinction of dialogic expansion and dialogic contraction turns on the degree to which an utterance, by dint of one or more of these locutions, actively makes allowances for dialogically alternative positions and voices (dialogic expansion), or alternatively, acts to challenge, fend off or restrict the scope of such (dialogic contraction) (Martin \& White, 2005).

The authors of this study find that there are about 964 researches concerning appraisal theory, 118 of which are about 
engagement system. Just as Wang \& Lu (2010) pointed out that compared with attitude and graduation sub-system, studies on engagement are relatively weak. Moreover, most of the researches on engagement system are about academic, political and news discourse. Few researches are based on global hot issue talk, which led to a gap to be fulfilled. In view of this, with the aid of corpus tools UAM and Antconc, this paper takes 2018 BRICS talk as the corpus and the engagement system as the theoretical framework to explore the theme and interpersonal meaning of 2018 BRICS talk from a linguistic perspective. Specifically, this research aims to answer the following questions: 1) What is the keywords list of BRICS talk? 2) What are the features of distribution of 2018 BRICS engagement resources? 3) How did those engagement resources help to express and position speakers' points of view so as to realize interpersonal meaning in a heteroglossic discussion?

\section{Literature Review}

\subsection{Research on News Discourse}

In recent years, many scholars take the engagement system as framework to analyze news report, a large part of which focus on "Belt and Road Initiative". Jiang \& Chen (2017) choose the domestic "Belt and Road Initiative" news as research corpus and find that from micro perspective, the engagement strategies in each part (opening, detailed, explanation, background and comment parts) have their own unique characteristics while from a macro perspective, the dialogue space of discourse construction shows a repetitive and rhythmic discourse mode with the change of engagement strategies. Wei \& Li (2017) find that expansion resources are obviously higher than contraction resources, and "acknowledge" resources is the most frequently used, which indicates that the speaker intends to expand the dialogue space and the construction mode of news text is multi-dimensional and dynamic. Wang (2018) selects the commentary on the "Belt and Road initiative" from abroad news report in 2017 as corpus and finds that the foreign reports use disclaim resource to shape negative image of China and degrade the strategic objectives and significance of "Belt and Road initiative". Furthermore, the use of resources "entertain" weakens the opportunities and strengthens the negative factors in the implementation of "Belt and Roadinitiative".

Some studies are committed to investigating the similarities and differences of the frequency and distribution characteristics of engagement resources between domestic and foreign news reports on the same topic. Zhang \& Liu (2013) conduct a comparative analysis of two reports on Beijing haze and find that medias implicitly express the tendency of public opinion through the integration of monogloss and heterogloss strategies. Zhu (2015) analyzes two Chinese-English news discourses on the same theme from different reports: the Wall Street Journal and Southern Metropolitan Daily and finds that there are many similarities in expansion resources between Chinese and English news report discourses, while there are still great differences in contraction resources. Liu \& Xu (2018) select 100 English and Chinese editorials on the topic of national politics as corpus and find that English editorials choose different types of heterogloss engagement resources and use a large number of extra voices. While Chinese editorials employ more monogloss resources, Chinese editorial discourse is less dialogistic.

Li (2008) analyzes engagement resources in CCTV9 Dialogue program interview and finds that the engagement features of the narrative, question and answer parts of the interview have similarities and differences, and the use of engagement resources is influenced by the genre and register characteristics of TV news interviews. Li \& Zhang (2010) further find that the interlaced interaction of the engagement characteristics of various parts of TV news interviews forms a significant rhythmic pattern. With different communicative purposes, different parts of the interview present different characteristics of engagement. Such an interactive and interlaced process makes the whole interview's engagement characteristics present an up and down rhythmic pattern.

\subsection{Research on Political Speech Discourse}

Political discourse is different from other discourses because persuasiveness is the main purpose of interpersonal meaning, which makes this kind of discourse have a common feature, that is, contraction resources are much frequently used than expansive resources. Some Chinese scholars have conducted many studies on political discourses. For example, Wang (2012) takes Lincoln's Gettysburg speech as an example; Xi (2012) selects the inaugural speeches of eight famous Presidents in American history as sample discourses for analysis; Liu (2013) analyzes the engagement resources of Obama's deliver of message of Ben Laden's death; Luo (2017) discusses the engagement resources of Trump's victory speech on November 9, 2016. Sun (2018) analyzes the linguistic features of the televised debate between Trump and Hillary Clinton in the presidential election in 2016. Results of all the above studies show that political discourse prefers dialogue contraction resources, less employs external voice sources, strengthens self-authority, suppresses other voices and enhances the persuasive power of discourse. 


\section{Research Method}

\subsection{Data Collection}

This study aims to explore features of engagement resources distribution used by each speaker and the interpersonal meaning realized by using those engagement resources. To conduct the research, we obtained a 40-minute face-to-face discussion from the 2018 BRICS talk. The data was generated from the transcript which was downloaded from official website with necessary adjustments because the oral speeches unavoidably had some grammatical mistakes.

\subsection{Data Processing and Analytical Tools}

A corpus of BRICS talk discourses of all the five speakers was then established. Antcont was employed to find out the theme of BRICS talk by word list function, and then UAM Corpus Tool3 was applied to show both the general distribution of engagement resources of all the five speakers and the distribution of engagement resources of each speaker, which is helpful for further comparative analysis.

Both quantitative and qualitative approaches were adopted in this study. Quantitative approach was employed to figure out the most frequent word list of BRICS talk and to find out the features and frequency of engagement resources both in general and within each of the speaker's utterance. Qualitative approach is used to explore how speakers position their own voices among the multi-voices to realize interpersonal meaning. For this purpose, we adopted the engagement system proposed by Martin \& White (2005) as the theoretical and analytical framework, which is illustrated by Figure 1.

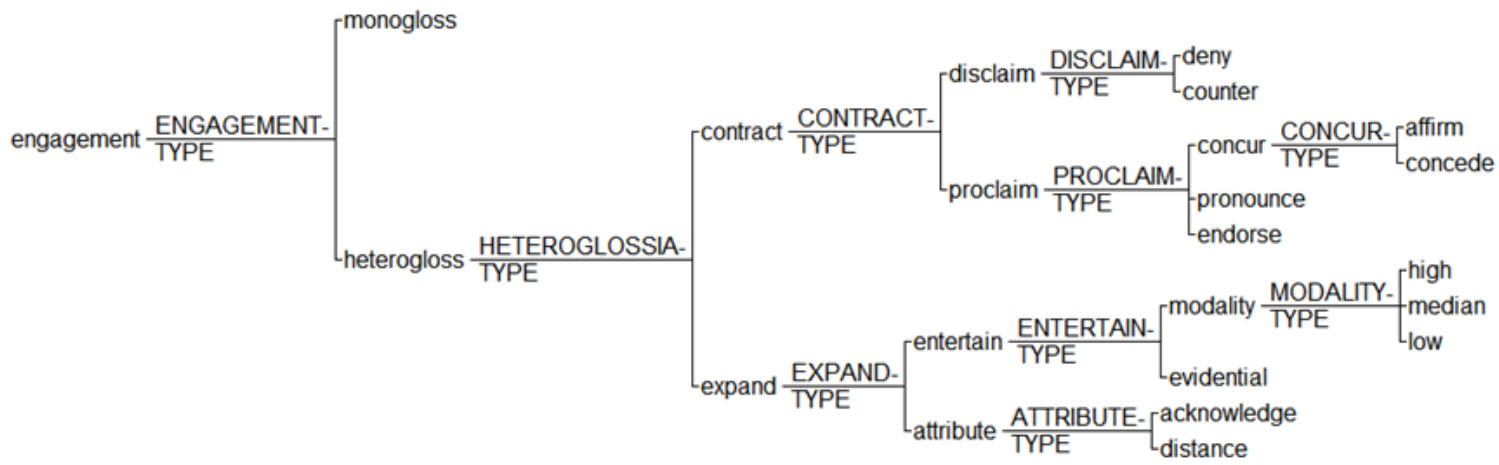

Figure 1. Theoretical framework of engagement system applied in this study

\section{Results and Discussion}

\subsection{Keyword List}

The word list and clusters functions of Antconc are employed to find out the theme of this talk. Cluster size is set from two to five, and minimum frequency is set to four, then functional words are removed from the list because they show nothing about the topic. Finally, the words and clusters with high frequency are shown in Table 1. It is found that the themes of 2018 BRICS talk are about cooperation, development, unilateralism, protectionism, opportunity for BRICS. Moreover, "South Africa", "Africa" and "African" have appeared 33 times in total which can be explained by the fact that in this talk, African speaker also shows his suspicion about whether African position is equal to other four BRICS members since it's the lasted one joining BRICS bloc. 
Table 1. Keyword list

\begin{tabular}{ll}
\hline Frequency & Word lists and clusters \\
\hline 33 & Africa (21) African (12) \\
24 & Trade \\
16 & China \\
16 & cooperation \\
16 & India \\
13 & Brazil \\
12 & Russia \\
11 & South Africa \\
11 & The BRICS \\
9 & development \\
8 & Industrial revolution \\
8 & investment \\
5 & protectionism \\
5 & In south Africa \\
4 & unilateralism \\
4 & opportunities for BRICS \\
\hline
\end{tabular}

\subsection{Heteroglossic Features and Realization of Interpersonal Meaning of 2018 BRICS Talk}

The following will focus on the heteroglossic features of distribution of 2018 BRICS engagement resources and how those engagement resources help to express and position speakers' points of view so as to realize interpersonal meaning in a heteroglossic discussion. As is shown in Table 2, the expansion resources accounting for $68.31 \%$ are much more frequently used than that of contraction accounting for $31.69 \%$, showing that speakers tend to open up the dialogic space and welcome different opinions from other BRICS members. It indicates that a harmonious discussion atmosphere is established in 2018 BRICS talk.

Table 2. The use frequency of expansion and contraction resources

\begin{tabular}{lll}
\hline Feature & $\mathbf{N}$ & Percent \\
\hline heterogloss & 243 & $100.00 \%$ \\
contraction & 77 & $31.69 \%$ \\
expansion & 166 & $68.31 \%$ \\
\hline
\end{tabular}

\subsubsection{Dialogic Expansion}

Dialogic expansion, divided into two subcategories: entertain and attribute, is to open up heteroglossic negotiation and extend the potential of construing heteroglossic diversity. As is shown in Figure 2, speakers tend to open dialogic space by entertain $(65.02 \%)$, more specifically, by modality $(65.02 \%)$ which accounts for the highest percentage within the engagement system. The figure shows that speakers are more willing to express their propositions through their inner voices by means of entertain instead of external voices by means of attribute resources. 


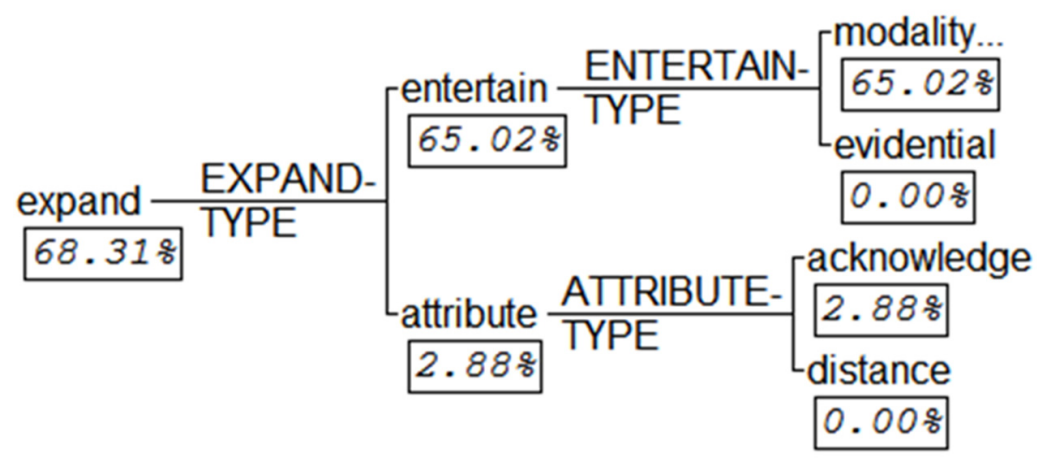

Figure 2. The use frequency of expansion resources

\subsubsection{Entertain}

Entertain refers to those wordings by which the authorial voice indicates that its position is one of a number of possible positions and thereby, to greater or lesser degrees, makes dialogic space for other possibilities. Martin \& White (2005) put forward that entertain can be further divided into modality and evidence-based resources. As is shown in Table 3, no evidence-based resources (it seems, it appears...) are used during this talk, and modality resources are realized by both explicit means, including modal auxiliaries (can, will, should, need...); modal adjuncts (probably, possibly, certainly...); and implicit means, including "I think", "In my view", "I believe", etc. In 2018 BRICS talk, there are a variety of opinions on global affairs which we have mentioned in the last chapter include cooperation, development, unilateralism, protectionism, opportunity for BRICS. Confronted with different points of view on the sensitive political issues, the speakers prefer to use modality to position their own opinions, which indicate that speakers are willing to embrace other different opinions and recognize that his proposition is just one among a number of propositions available in the current communicative context. According to Halliday (2004), modality can be divided into "high", "median" and "low". The classification depends on how much dialogic space it leaves for alternative opinions. From Table 3, it is obvious that, in order to maintain friendly interpersonal relationship, all speakers of BRICS members prefer to use median modality resources (41.15\%), followed by low modality resources (18.11\%), and high modality resources $(5.76 \%)$ account for the least. Median and low values of modality make it easier for audience to accept their points of view and helpful to establish solidarity and harmony with other BRICS members, thus providing more tolerance for the dialogue and showing respect for the audience.

Table 3. The use frequency of high, median and low value of modality

\begin{tabular}{lllllllllllll}
\hline \multirow{2}{*}{ MODALITY } & \multicolumn{2}{l}{ Total } & \multicolumn{3}{c}{ Africa } & \multicolumn{2}{c}{ Brazil } & \multicolumn{2}{c}{ China } & \multicolumn{2}{l}{ India } & \multicolumn{2}{c}{ Russia } \\
\cline { 2 - 13 } & $\mathrm{N}$ & percent & $\mathrm{N}$ & percent & $\mathrm{N}$ & percent & $\mathrm{N}$ & percent & $\mathrm{N}$ & percent & $\mathrm{N}$ & percent \\
\hline high & 14 & $5.76 \%$ & 0 & $0.00 \%$ & 4 & $7.02 \%$ & 1 & $2.56 \%$ & 3 & $5.45 \%$ & 6 & $9.68 \%$ \\
\hline median & 100 & $41.15 \%$ & 13 & $43.33 \%$ & 23 & $40.35 \%$ & 18 & $46.15 \%$ & 23 & $41.82 \%$ & 23 & $37.10 \%$ \\
\hline low & 44 & $18.11 \%$ & 2 & $6.67 \%$ & 14 & $24.56 \%$ & 3 & $7.69 \%$ & 17 & $30.91 \%$ & 8 & $12.90 \%$ \\
\hline
\end{tabular}

(1) Brazilian speaker: So we have to change the pattern of the economic cooperation.

By using a few high value modality resources, speakers show their confidence to win over other BRICS members on particular issue. In example (1), "have to" belongs to modulation, as Halliday and Matthiessen (2004) present, when modality is used to argue about the obligation or inclination of proposals, it is referred to as modulation. Brazilian speaker use "have to" to represent an obligation to change the trade mode, just as what he has mentioned "I mean China has been a main employer..." By using such high value modality "have to", Brazilian speaker shows that he is not satisfied with the trade mode within BRICS and has made his determination to take action to change the trade mode so as to become an investor to other countries rather than a recipient of other countries, especially a recipient of China.

(2) African speaker "So Africa maybe will get the opportunity to focus us more to China with its trade and economy, and also this will offer an opportunity for BRICS institution to streamline themselves on the African territory."

All the modality recourses African speaker uses belong to median and low value. In example (2), "maybe" belongs to 
low value modality and "will" belongs to median value modality. Africa, as the lasted member joining in BRICS and the weakest comprehensive national strength in the BRICS bloc, does feel its country may not be treated equally. Therefore, to some respect, he tries to avoid those assertive expressions like high value modality. By using median and low values of modality resources, African speaker degrades the sharpness to make the dialogic space more open, so as to entertain others' voices, thus, addressees will be more willing to accept his point of view, or at least, not so resistant with his opinions.

\subsubsection{Attribute}

Martin \& White (2005) put forward that there are two sub-categories of attribution. The first one is "acknowledge", which shows no overt indication of where the authorial voice stands with respect to the proposition. The second one is distance which involves formulations present an explicit distancing of the authorial voice from the attributed material. These two attribute resources have different rhetorical functions in construing interpersonal meaning. As is shown in Table 4, acknowledge resources account for $2.88 \%$ and distance resource is not used. In BRICS talk, speakers tend to use acknowledge to position themselves as engaging interactively with the opinion they attribute instead of distance resources which indicate an obvious distancing and alienation of the authorial voice from the attributed utterance.

Table 4. The use frequency of attribute

\begin{tabular}{|c|c|c|c|c|c|c|c|c|c|c|c|c|}
\hline \multirow{2}{*}{ Attribute } & \multicolumn{2}{|c|}{ Total } & \multicolumn{2}{|c|}{ Africa } & \multicolumn{2}{|c|}{ Brazil } & \multicolumn{2}{|c|}{ China } & \multicolumn{2}{|c|}{ India } & \multicolumn{2}{|c|}{ Russia } \\
\hline & $\mathrm{N}$ & percent & $\mathrm{N}$ & percent & $\mathrm{N}$ & percent & $\mathrm{N}$ & percent & $\mathrm{N}$ & percent & $\mathrm{N}$ & percent \\
\hline acknowledge & 7 & $2.88 \%$ & 1 & $3.33 \%$ & 3 & $5.26 \%$ & 1 & $2.56 \%$ & 2 & $3.64 \%$ & 0 & $0.00 \%$ \\
\hline distance & 0 & $0.00 \%$ & 0 & $0.00 \%$ & 0 & $0.00 \%$ & 0 & $0.00 \%$ & 0 & $0.00 \%$ & 0 & $0.00 \%$ \\
\hline
\end{tabular}

(3) African speaker. "The present BRICS, as president Xi Jinping stated very well, this marks a golden decade of BRICS.”

Among all the five speakers, only African speaker shows great authorial judgement of the attribute resources. In example (3), as what Martin \& White (2005) have mentioned, in such case, the monoglossia of the attitudinal assessment 'very well' over-rides the heteroglossia of the attribution "as president Xi Jinping stated", presenting that the speaker is aligned with a given proposition and thereby bidding to align the audience into this point of view. High credibility is implied by attributing this voice to Xi Jinping who has high status and authority. Although it is from external source, the speaker is presented as very supportive to this point of view by the monoglossia of the attitudinal assessment "very well".

(4) Brazilian speaker "After we talk with agriculture section which is quite organized section and Brazil nowadays, there are also some constraint mid-term and long-term effect."

Among all the other four speakers. The attribute resources they quote are mainly from two sources without any obvious authorial attitudes involved. One is authority institution, in example (4), "the Brazil sector agriculture section" shows that the following information "there are also some constraint mid-term and long-term effect." is believable and valid.

(5) Chinese speaker "I agree with the ambassador what he said about looking inside, and try to break down barriers between the countries within BRICS".

The other source of attribute resource comes from other four speakers, which shows that speakers are willing to maintain a friendly relationship by acknowledging other four BRICS speakers' points of view. In example (5), Chinese speaker associates external voices that are from "Indian ambassador" with that his inner voice "agree with", presenting the authorial voices as recognize Indian ambassador's opinion. In 2018 BRICS talk, speakers tactically employ acknowledge resources from external voices in order to make their arguments fair and objective.

\subsubsection{Dialogic Contraction}

Dialogic contraction is used to challenge or fend off alternative positions, which includes disclaim and proclaim. As it is shown in Table 5, disclaim resources accounting for $23.64 \%$ are used much more frequently than proclaim accounting for $8.23 \%$, showing that speakers from BRICS bloc prefer to contract dialogic space by deny and counter, which is to acknowledge other speakers' points of view so as to reject them or regard the proposition as counter expectation. 
Table 5. The use frequency of contraction resources

\begin{tabular}{lll}
\hline Contraction & N & Percent \\
\hline Disclaim & 57 & $23.46 \%$ \\
\hline proclaim & 20 & $8.23 \%$ \\
\hline
\end{tabular}

\subsubsection{Disclaim}

Disclaim refers to the formulations by which some prior utterance or some alternative position is invoked so as to be directly rejected, replaced or held to be unsustainable. Disclaim $(23.46 \%)$ is the second most frequent resources used in the BRICS talk. As is shown in Table 6, among the five speakers, speakers from Africa (33.33\%), China (41.03\%) and Russia (29.03\%) use disclaim resources more frequently than that of Brazil (12.28\%) and India (10.91\%). Disclaim is further divided into two sub-types: deny and counter. Deny refers to introducing an alternative position into the dialogue, and hence acknowledging it, so as to reject it. Counter refers to formulations which represent the current proposition as replacing or supplanting, and thereby "countering" a proposition which would not have been expected in its place. With regard to disclaim resources, the use frequency can explain little of the implied interpersonal meaning, instead, it is the topics on which the disclaim resources are used that really count, therefore, the following section will go for each of the speaker to find out disclaim resources are used on what subjects and to reject what opinions by the five speakers.

Table 6. The use frequency of disclaim resources

\begin{tabular}{|c|c|c|c|c|c|c|c|c|c|c|}
\hline \multirow{2}{*}{ Resource } & \multicolumn{2}{|c|}{ Africa } & \multicolumn{2}{|c|}{ Brazil } & \multicolumn{2}{|c|}{ China } & \multicolumn{2}{|c|}{ India } & \multicolumn{2}{|c|}{ Russia } \\
\hline & $\mathrm{N}$ & percent & $\mathrm{N}$ & percent & $\mathrm{N}$ & percent & $\mathrm{N}$ & percent & $\mathrm{N}$ & percent \\
\hline disclaim & 10 & $33.33 \%$ & 7 & $12.28 \%$ & 6 & $41.03 \%$ & 6 & $10.91 \%$ & 18 & $29.03 \%$ \\
\hline
\end{tabular}

(6) African speaker "And instead of the sanctions that we see now or the trade war that is occurring now, instead of looking them as a big problem, let's look them as an opportunity to readdress the trade."

(7) African speaker: "If it's a problem it's merely a trading glitch which all has. But also what is happening with United States now is not United States that should be in question."

African speaker employs disclaim resources to deny and reject the seriousness of the current situation and shows great confidence in BRICS bloc. In example (6), African speaker introduces the alternative opinions about American protectionism and unilateralism, which are: "looking them as a big problem." and "it's a problem." so as to use deny resources to reject those opinions, then put forward his own point of view "look them as an opportunity to readdress the trade." In example (7) counter resource "but" is used to show that the problem is not on United States, what should be in question is whether BRICS bloc will cooperate or not. The use of "merely" indicates that African speaker has confidence to win over other speakers or audiences who hold that the situation is seriously bad now.

(8) African speaker: "But what I had a little bit from the past talk, just a little bit, is sound respect."

In example (8), disclaim resource is also used to show Africa's suspicion about whether African position is equal to other four BRICS members since it's the lasted one joining BRICS bloc. When speakers use "but", the information after "but" is much more important than the information before "but". So here, what African speaker wants to emphasize is that he is concerned and worried about sound respect. Though he tries to use "a little bit" (graduation resource) to degrade such concern in order to keep harmonious relationship with other BRICS members, the counter resource "but" let out that he is really concerned about African position in BRICS bloc.

(9) Brazilian speaker: "Well, I do believe that we do can expand that and it's not the point... it's a creative acronym and nothing will block us into expanding that."

In example (9), Brazilian speaker uses disclaim resources "not", "nothing" to reject the difficulty of thinking up a new name for BRICS members if there is any other country to join in, which indicates that he is willing to welcome any country who wants to join in BRICS bloc.

(10) Brazilian speaker: "I think traditionally Brazil has been the recipient of foreign investments rather than investing in other countries."

(11) Brazilian speaker: "I mean China has been a main employer, but more recently...there was a lot of change, 
we've seen a lot of show ups in the Indian companies."

Brazilian speaker indicates that Brazil is ready to diversify its trade. In the above examples (10), Brazilian speaker uses "rather than" to show that Brazil is a recipient of foreign investments instead of an investor to other countries. In example (11), what Brazilian speaker wants to emphasize is the information after "but", that is, since the situation is changing, Brazil will seize every possible opportunity to diversify its trade partner and become an investor to other countries.

(12) Chinese speaker: "However, I think this is not an either-or question. On the one hand, we should improve and make the mechanism work better among ourselves but on the other hand we need to unite against the rising tide of protectionism and unilateralism from the United States."

Chinese speaker uses disclaim resources to contract the dialogic space to show China is against protectionism and unilateralism, therefore anyone who poses different opinions on this issue will cost a lot of interpersonal relationship to address opposite viewpoint. In example (12), what Chinese speaker wants to reject is Indian speaker who pays more attention to restrictions on trade within BRICS rather than American sanctions. Here, Chinese speaker uses "not" to show disagreement with Indian speaker and the use of "however" and "but" are to attract other speakers' attention to the fact that protectionism and unilateralism should also be paid attention to.

(13) Chinese speaker: "I want to emphasize this, I think there is only a group of people within the United States holding these ideas. This does not represent everything from the United States." "And we should unite not only among ourselves, but also we should accept, you know, that part of the United States who still believe that free trade is the pillar of modern society..."

In example (13), The proposition that "part of the United States believe that free trade is the pillar of modern society" is interpreted as counter expectation since most of the addressees' normal expectation should be "American support protectionism and unilateralism". Such counters are aligning rather than disaligning because addresser is presented just as surprised at the unexpected results as the addressee, (Martin \& White, 2005). "only", "not", and "but" are used to show Chinese speaker believes that part of the United States still believe that free trade is the pillar of modern society.

(14) Indian speaker: “...markets are being opened up by the developed countries has helped all the developing and emerging economies...either unilateralism or protectionism does not help us at all."

Indian speaker uses disclaim resources to show opposition to American sanctions. According to the target addressee of the denial, Martin and White (2005:118) divided denial into two types. One is that the denial is directed outwards and away from the current writer-reader relationship as the writer indicates a disalignment with some third party, which is the case with example (14), the speaker indicates a disalignment with the views of "unilateralism or protectionism is helpful" and by doing so aligns the audience into a position which is opposed to this opinion. He supplies argumentative material "markets are being opened up by the developed countries has helped all the developing and emerging economies", to support his negation of "unilateralism or protectionism is helpful", construing the listeners or those who hold opposite opinion as possibly still need to be convinced or at least require more information on the subject.

(15) Indian speaker "But I think we have to then also look at our own policies... So there is a great deal of advantage and this can only come about if we look upon ourselves as setting an example to the rest of the world, even at a time when we are being challenged by protectionism, by unilateralism and so on."

In example (15), Indian speaker uses disclaim resources to negate the seriousness of unilateralism and protectionism, instead, he believes that most of the problems are caused by the trade barrier within BRICS. Disclaim resources "but", "only", and "even" express Indian speaker's opinion to a large extent, the problem is mainly caused within BRICS. He used "even" to show that though some other BRICS members believe the protectionism and unilateralism are very serious, he still believes if there are not any problems within BRICS member, protectionism and unilateralism won't bring serious consequences.

(16) Russian speaker: "Because it's not enough to trade the economy of the $21^{\text {st }}$ century ... but also I think for Russia it is important to diversify as much as possible its own trade ...I think that Russia can definitely engage in not just bilateralism cooperation but in joint projects with China and with India."

Russian speaker employs disclaim resources to contract dialogic space on the cooperation issue, showing his inclination to diversify trade. In example (16), the denial resource "not" invokes and presents itself as responding to the current situation of trade mode, which means Russia exports primarily gas and oil and other raw materials to 
China, and in exchange, it gets finished goods. By using "but", "only”, Russian speaker emphasizes "for Russia, it is important to diversify as much as possible its own trade".

\subsubsection{Proclaim}

Proclaim resources are divided into three subcategories: concur, pronounce and endorse, by which dialogic alternatives are confronted, challenged, overwhelmed or excluded through some authorial interpolation, emphasis or intervention. As is shown in Table 7, proclaim only takes up $8.23 \%$ in the whole engagement system. And its subcategories: concur accounts for $2.06 \%$, pronounce $6.17 \%$ and no endorse resource is used. It is obvious that there are far less proclaim resources than disclaim resources. It may be because proclaim resource shows obvious personal intervention of the opinion, thus the arguments will be personalized which will weaken the persuasion.

Table 7. The use frequency of proclaim resources

\begin{tabular}{|c|c|c|c|c|c|c|c|c|c|c|c|c|}
\hline \multirow{2}{*}{ proclaim } & \multicolumn{2}{|c|}{ Total } & \multicolumn{2}{|c|}{ Africa } & \multicolumn{2}{|c|}{ Brazil } & \multicolumn{2}{|c|}{ China } & \multicolumn{2}{|c|}{ India } & \multicolumn{2}{|c|}{ Russia } \\
\hline & $\mathrm{N}$ & Percent & $\mathrm{N}$ & percent & $\mathrm{N}$ & percent & $\mathrm{N}$ & percent & $\mathrm{N}$ & Percent & $\mathrm{N}$ & Percent \\
\hline concur & 5 & $2.06 \%$ & 0 & $0.00 \%$ & 2 & $3.51 \%$ & 0 & $0.00 \%$ & 1 & $1.82 \%$ & 2 & $3.23 \%$ \\
\hline pronounce & 15 & $6.17 \%$ & 3 & $10.00 \%$ & 4 & $7.02 \%$ & 0 & $0.00 \%$ & 3 & $5.45 \%$ & 5 & $8.06 \%$ \\
\hline endorse & 0 & $0.00 \%$ & 0 & $0.00 \%$ & 0 & $0.00 \%$ & 0 & $0.00 \%$ & 0 & $0.00 \%$ & 0 & $0.00 \%$ \\
\hline
\end{tabular}

(17) Brazilian speaker: "Obviously, the process is not that easy, I think."

Concur involves formulations which overtly announce the addresser as agreeing with, or having the same knowledge as, some projected dialogic partner. Typically, this dialogic partner is the text's putative addressee, (Martin \& White, 2005). Such formulations are contractive in that they represent the shared belief "the process (development process of BRICS) is not that easy" as universally, or at least as very widely recognized in the BRICS bloc context. Thus the speaker excludes and alienates any extremely positive alternative opinions which believe "it will be easy for BRICS bloc to develop to grow" from the ongoing colloquy, because whoever advances an opposite alternative is contradictory with what is universally agreed upon or recognized.

(18) Brazilian speaker: "Yes, at the very beginning, the short term, it's very beneficial, but there is a very issue to be concerned, in long term, in will bring difficulties to agriculture section in Brazil."

Concede, a sub-system of concur, often occurs as a precursor to a countering. Martin \& White (2005) put forward that there are two interlinked rhetorical moves here (a rhetorical pair) by which the authorial voice first presents itself as agreeing with the construed addressee with respect to a proposition, only to step back, and to indicate a rejection of what are presented as the natural assumptions arising from that initial proposition. In example (18), there are two interlinked rhetorical moves, "yes" and "but". By using "yes", the speaker presents the position "at the very beginning, the short term, it's very beneficial" as generally recognized within BRICS members, but in the following sentence, the employment of counter resource "but" indicates a rejection of what is supposed to be the natural assumptions arising from the initial proposition after "yes". By the concession, the speaker validates the viewpoint "at the very beginning, the short term, it's very beneficial", after acknowledging that it is understandable and has a rational basis, then, Brazil speaker denies the previous opinion and emphasizes the following massage that it will bring more difficulties to Brazil.

(19) Russian speaker: "Well, of course, the world is very different from what it was some 50 years ago Russia and USA cold war. But I think that for Russia, Africa is still underinvestment portfolio."

In example (19), two interlinked rhetorical moves, "of course" and "but" are used to present the authorial voice acknowledges the "the world is very different from what it was some 50 years ago" which is assumed to be widely admitted by other four speakers. So that means there will not be another cold war between Russia and America. Then he uses "but" to further points out that though the current global situation is different from 50 years ago, Russia will still pay attention to the trade with Africa. Therefore, argumentative ground is given up initially, namely, the situation is different, so as to provide the ground for the subsequent counter move, showing Russia is willing to invest Africa, thus, further presenting a friendly and harmonious relationship with Africa.

(20) African speaker: "What should be in question is that how ready south-south cooperation and BRICS is being able to use the institution that they have established." 
Martin \& White (2005) put forward that the category of pronounce covers formulations which involve authorial emphases or explicit authorial interventions or interpolations. For example: I contend ..., The facts of the matter are that ..., The truth of the matter is that ..., We can only conclude that ..., You must agree that ..., intensifiers with clausal scope such as really, indeed, etc. These authorial interventions are directed towards confronting and defeating a contrary position, and then, identify authorial interpolations and emphases which are directed against some assumed or directly referenced counter position. In example (20), "What should be in question" constitutes an overt intervention into the discussion by the speaker's voice - the point is "how ready south-south cooperation and BRICS is able to cooperate". The employment of pronounce indicates that African speaker firmly believes that if the BRICS members can cooperate, American sanction is not an issue at all, showing his great confidence and positive attitudes towards the power of BRICS bloc. The speaker's voice "What should be in question" makes more salient its subjective role by totally recognizing his own proposition. Thus, the interpersonal cost to whoever poses a contrary position is increased and the dialogic space for this alternative in the upcoming dialogic interaction is narrowed.

\section{Conclusion}

This paper explores the theme, the features of distribution of 2018 BRICS engagement resources and how those engagement resources help to express and position speakers' points of view so as to realize interpersonal meaning in a heteroglossic discussion from a linguistic perspective. The theme of 2018 BRICS talk is about cooperation, development, unilateralism, protectionism, opportunity for BRICS. With regard to the features of distribution of 2018 BRICS engagement resources, the expansion resources accounting for $68.31 \%$ used by the five speakers are much more than that of contraction accounting for $31.69 \%$. Within expansion resources, speakers tend to open dialogic space by entertain (65.02\%), more specifically, by median and low value modality and attribute others opinions to open up the dialogic space and welcome different opinions from other BRICS members, which enables a harmonious discussion atmosphere to be established in 2018 BRICS talk. As far as attribute is concerned, acknowledge accounts for $2.88 \%$ and distance resource is not used, which indicates that in BRICS talk, speakers employ acknowledge resources to position themselves as engaging interactively with the opinion they attribute. Within contraction resources, disclaim resources accounting for $23.64 \%$ are used much more frequently than proclaim accounting for $8.23 \%$. Less adoption of proclaim resource can be explained by the fact that proclaim shows obvious personal intervention of the opinion, thus, the arguments will be personalized which will weaken the persuasion. The preference for disclaim resources indicates that speakers prefer to contract dialogic space by deny and counter, which means acknowledging other speakers' points of view so as to reject them or regarding the proposition as counter expectation. According to Martin \& White (2005), the employment of disclaim resources is at the cost of losing interpersonal harmony with those who pose different opinions. Therefore, the topic on which disclaim resource is used must be something the speakers are really concerned about. In the above discussion, it is found that some speakers use disclaim resources such as "but, however, merely, only, even" to negate the seriousness of the U.S. trade protectionism, and point the finger at the internal trade problems of the BRICS, which implies that under the prevalence of unilateralism and trade protectionism, it is advisable for the BRICS to pose a far more determined opposing attitude towards trade protectionism, rather than pointing the finger at BRICS bloc, and it is particularly important for emerging markets to unite with each other to fight against protectionism and promote common development.

There is no denying the fact that there are some limitations in this study. First of all, appraisal theory, as an extension of Halliday's interpersonal meaning, consists of three subsystems. This paper only focuses on the characteristics and interpersonal meaning of engagement resources and does not draw any attention to attitude and graduation. Secondly, in the analysis of engagement resources, although the authors make every possible effort to respect the linguistic facts, but still inevitably bring some subjective factors and may reduce the objectivity of this paper. Last but not least, this paper is devoted to exploring the promising emerging markets' opinions on trade protectionism, unilateralism from the perspective of engagement system. However, the potential emerging markets include not only BRICS bloc, therefore the corpus in this paper may be limited, but still, it attempts to appeal to scholars for their attention to the research on diversified global hot topics from linguistic perspectives.

\section{References}

Bakhtin (1998). Works of Bakhtin (Volume 4). Shijiazhuang: Hebei Education Press.

Halliday, M. A. K., \& Matthiessen, C. (2004). An Introduction to Functional Grammar (3rd ed.). London: Hodder Arnold.

Jiang G. D., \& Chen, X. (2017). "One Belt, One Road" in Foreign News-Discourse Analysis under the Engagement System of Appraisal Theory. Foreign Languages Research, 34(05), 6-9. 
https://doi.org/10.13978/j.cnki.wyyj.2017.05.002

Li, J. (2008). Analysis of Multi Voice of TV News Interview from the Perspective of Appraisal Theory. Ocean University of China.

Li, J., \& Zhang, D. L. (2010). Prosodic Pattern of Engagement in TV News Interviews. Foreign Language Education, 31(04), 6-10+19. https://doi.org/10.16362/j.cnki.cn61-1023/h.2010.04.027

Liu, S. H. (2013). Exploration on Interpersonal Meanings of Speeches from the Engagement Perspective-Based on Obama's Speech on Bin Laden's Death. Journal of Hubei University of Education, 30(04), 15-17.

Liu, T. T., \& Xu, J. X. (2018). A contrastive study on Engagement resources in English and Chinese editorials -An appraisal theory perspective to the journalistic discourse. Foreign Language and Translation, 25(03), 45-51. https://doi.org/10.19502/j.cnki.2095-9648.2018.03.008

Luo, J. (2017). Analysis of Trump's Winning Speech from the Perspective of Appraisal Theory. Journal of Suzhou University, 32(09), 65-68.

Martin, J. R., \& White, P. R. R. (2005). The Language of Evaluation: Appraisal in English. New York: Palgrave Macmillan Ltd. https://doi.org/10.1057/9780230511910

Sun, Y. (2018). An analysis of the Engagement Resources in US Presidential Debates. Lu Dong University.

Wang, C. L. (2012). Engagement Resources Analysis of the Speech Style from the Perspective of Dialogue: A Case Study of Gettysburg Speech. Journal of Mudanjiang Institute of Education, 2012(02), 36-37.

Wang, J. (2018). Engagement Resources of the Belt and Road Initiative Discourse in the American Think Tank: A Case Study of Carnegie Endowment for International Peace. Journal of Suzhou University, 33(04), 75-81.

Wang, Z. H., \& Lu, Y (2010). A Reflection on Engagement Systems. Foreign Language Journal, 2010(3). https://doi.org/10.16263/j.cnki.23-1071/h.2010.03.010

Wei, B. W., \& Li, C. J. (2017). Dialogism in News Discourse of Strategic Conception of "One Belt and One Road" in China. Journal of Jixi University, 17(01), 133-138. https://doi.org/10.16792/j.cnki.1672-6758.2017.01.029

Xi, X. Q. (2012). Research on Intervention Resources in Inaugural Speech Discourse. Journal of Xinjiang University, 40(01), 151-156. https://doi.org/10.13568/j.cnki.issn1000-2820.2012.01.011

Zhang, Y. Z., \& Liu, J. (2013). Dialogism in News Discourse from the Perspective of Engagement System. Journal of Mudanjiang University, 22(06), 116-118. https://doi.org/10.15907/j.cnki.23-1450.2013.06.021

Zhu, R. (2015). Engagement Resource Analysis of Chinese English News Discourse from the Perspective of Dialogism-Take the Reports of the Wall Street Journal and the Southern Metropolis Daily for Example. Journal of Chizhou University, 29(04), 94-97. https://doi.org/10.13420/j.cnki.jczu.2015.04.020 